\title{
Epistemology Mathematicized
}

\section{JoHN WoODS}

\author{
University of British Columbia \& University of Lethbridge \\ Department of Philosophy \\ University of British Columbia \\ 1866 Main Mall E370 \\ Vancouver, $B C$ \\ Canada V6T 1Z1 \\ john.woods@ubc.ca
}

\begin{abstract}
Epistemology and informal logic have overlapping and broadly similar subject matters. A principle of methodological symmetry is: philosophical theories of sufficiently similar subject matters should engage similar methods. Suppose the best way to do epistemology is in highly formalized ways, with a large role for mathematical methods. The symmetry principle suggests this is also the best way to do the logic of the reasoning and argument, the subject matter of informal logic. A capitulation to mathematics is inimical to informal logicians, yet formal methods and mathematical models are an emerging force in epistemology. What is to be done? What's sauce for the goose of epistemology is sauce for the gander of informal logic.
\end{abstract}

Résumé: L'épistémologie et la logique non formelle partagent des sujets à peu près similaires. Selon un principe de symétrie méthodologique, des théories philosophiques de sujets suffisamment similaires devraient employer des méthodes similaires. Supposons que la meilleure façon de faire l'épistémologie est extrêmement formalisée, et a un rôle important pour les méthodes mathématiques. Le principe de symétrie suggère que c'est aussi le meilleur moyen de faire la logique du raisonnement et de l'argumentation, ce qui est l'objet de la logique informelle. Une capitulation aux mathématiques est hostile aux logiciens non formels, mais les méthodes formelles et les modèles mathématiques sont une force émergente dans l'épistémologie. Que faut-il faire? Ce qui est bon pour l'oie de l'épistémologie est bon pour l'autre de la logique non formelle.

Keywords: Bayesianism, conceptual adequacy, formal argumentation, formal epistemology, informal logic, mathematical, normative arithmetic, symmetry principle 
On [the] traditional view of the subject, the phrase 'formal logic' is pleonasm and 'informal logic' oxymoron. John Burgess

\section{Keeping mathematics in its place}

Notwithstanding their growing influence in epistemology and their established presence in probability theory and decision theory, mathematical methods haven't had much play in mainstream informal logic. ${ }^{1}$ It is true that informal logic (IL) theorists tend to concede to modern formal logic a role in characterizing the notion of formal validity, and to the probability calculus a role in characterizing the relation of inductive strength. But by and large these developments are borrowed from the areas of enquiry in which they first arose, and informal logicians don't often involve themselves in the further theoretical advancement of those disciplines. A smallish exception is the use of computational methods to model dialogical argument. ${ }^{2}$ Even so, most IL people who approach their work dialogically ignore or reject the more aggressively mathematical character of formal work in logics of dialogues and games. ${ }^{3}$

Informal logicians have met with success in characterizing modes of reason and argument which instantiate structures not well-caught (or catcheable at all) even in the run of the mill formalisms to which the IL community pays lip-service. A good example of this are contributions of Trudy Govier and others to the logic of

\footnotetext{
1 "Mainstream informal logic" is a flexible expository convenience. As used here it signifies literatures of the sort generated by the journals of record, Informal Logic and Argumentation, and the monograph series Argumentation Library (Springer) and Studies in Logic and Argumentation (College Publications), as well as the numerous Proceedings of ISSA Conferences (Sic Sat). See also Johnson (1996).

${ }^{2}$ See, for example, Reed and Norman (2003) and, more recently, the journal Argument and Computation.

${ }^{3}$ See, for example, Walton and Krabbe (1995) and Walton (1998). An important exception is Barth and Krabbe (1982). More extreme recent exceptionscertainly exceeding the reach of "informal logic" - are Barringer et al. (2012a) and (2012b). For something more accessible, but robustly technical, see Weinstein (2013).
}

(C) John Woods. Informal Logic, Vol. 33, No. 2 (2013), pp. 292-331. 


\section{John Woods}

conductive argument. ${ }^{4}$ So far as I know, no one in the IL camp has thought to approach this logic by way of mathematical models. It is not hard to see why. One of the more dominant IL ideas is that mathematics doesn't pay the freight in these branches of enquiry. If we search the IL literature we aren't likely to find much, if anything, in the way of systematic demonstration of this sentiment. An indifference to mathematical entanglements, if not an outright hostility to them, is IL's default position. Still, perhaps the time has come for a bit more aggression. If mathematical models are not the way to go in the logics of everyday reasoning and argument, wouldn't there be some value in actually showing this to be so?

Of course, "paying the freight" is a metaphor. In its weakest sense, mathematics pays (some of) the freight in a theory when it has the ancillary role of expository convenience. At more extreme levels, there will be a degree to which non-mathematical content is infiltrated by the theory's strictly mathematical requirements. In which case, not only does mathematical modelling "pay the freight." To a non-trivial degree it also "calls the shots."

There is substantial though not universal agreement among informal logicians that the mechanisms driving the human animal's behaviour as a reasoning and case-making being are of the same general family as those that serve his further cognitive endsdecision making, planning, belief formation, belief change, inference, and so on. So seen, since reasoning and case-making are themselves broadly epistemic enterprises, their respective theories should reflect this kinship in correspondingly appropriate ways. ${ }^{5}$ We might say at a minimum that, except for cause, subject matters of like type require theories of like type. This is the Symmetry

\footnotetext{
${ }^{4}$ See here Govier (1980) and Blair and Johnson (2012). See also Hitchcock (2013).

${ }^{5}$ For further discussion, see Johnson (2007). See also Siegel and Biro (1997), Biro and Siegel (2006) and (2011), Freeman (2005), Finocchiaro (2005) and (2013), and Woods (2013a). I don't want to overlook the frequency with which both argumental and reasoning practices are directed to non-cognitive ends. But they are practices which nonetheless deeply implicate the procedures involved in the advancement of those agendas.
}

(C) John Woods. Informal Logic, Vol. 33, No. 2 (2013), pp. 292-331. 
Principle. Since the correspondences are loose rather than one-toone tight, the Principle in turn is more approximate than strict. But I would say that it give symmetry enough to be getting on with.

This would be the right place to take particular note of rising tide in the theory of knowledge. It is the progressive entrenchment of formal epistemology as an established rival of analytic and naturalistic approaches. ${ }^{6}$ Of the three, perhaps it is formal epistemology that hasn't quite made it into the mainstream. But its prospects for promotion are far from bad; indeed they are brimming. ${ }^{7}$ The formal epistemologies I want to consider make a serious claim to mathematical robustness. They are epistemologies in which mathematics pays a good deal of the freight and calls some of the important shots.

Perhaps there are some informal logicians who are ready to accept the prospects of formal encroachment with a certain equanimity. But I hardly think that, if any at all, these brave souls exist in any numbers to speak of. This leaves the majority with three options. One is to overturn the Symmetry Principle. Another is to disarm formal argumentation theory head-on. The third is to retain the Symmetry Principle and to deal with formal epistemology heads on. Of the three, the third strikes me as the best bet. The first is implausible on its face. The second is discouraged by the fact that the wholesale invasion of informal logic by aggressively mathematical methods of argument has barely begun to happen. In contrast, for-

\footnotetext{
${ }^{6}$ See, for example Gärdenfors (1988), Hendricks (2005) and Shoham and Leyton-Brown (2009). Except for one chapter, all of Hendricks (2005) is a survey of formal epistemologies, and the book's large bibliography is almost entirely devoted to their literatures. On the other side, modern analytic epistemology is in the abundant slipstream of the conceptual analyses favoured by Moore and Russell. Modern developments in naturalized epistemology, also by now wellestablished, ensue from Quine (1969).

${ }^{7}$ See again the journal Argument and Computation, especially, the guest editor's note of volumes 2-3 of 2012 (van Benthem, 2012a, 2012b). See also the "formal models" sections of Gabbay and Woods (2003a) and (2005). A standard formalist textbook is Besnard and Hunter (2008). It is worlds away from Govier (2013), Johnson and Blair (2006) and, yes, from Woods, Irvine and Walton (2004) as well.
}

(C) John Woods. Informal Logic, Vol. 33, No. 2 (2013), pp. 292-331. 


\section{John Woods}

mal epistemology now lays fair claim to a permanent seat at the councils of mainstream theory of knowledge. It offers us a bigger target, more settled and more easily hit. ${ }^{8}$

\section{Modelling human behaviour}

Here now are two different approaches to the role of formal models in philosophical enquiry at large, not just epistemology.

Now that we all understand the virtues of a model-theoretic semantics satisfying general Montagovian standards of rigour and clarity, there is joy in playing around with virtually every specific detail of Montague's original paradigm. The following ... illustrate various aspects of this new wave of free speculation....

Johan van Benthem (van Benthem 1979), p. 337)

There may be principles so central that anyone who rejects them and nonetheless uses the usual name for the concept may be said not to be using the usual concept but another of the same name. Such principles may perhaps be called "conceptual," and by those who accept them as truths, "conceptual truths." We may perhaps be hypothetically obliged to accept them as true if we accept the concept. But we are not categorically obliged to accept them as true, since we are not obliged to accept the concept. We may even on the contrary be obliged to reject the concept ....

John Burgess (Burgess 1998, p. 142)

I want to examine the tensions exhibited in this pair of remarks. For ease of future reference we might call these the "Benthemite"

\footnotetext{
${ }^{8}$ Naturalized epistemology has made the "big time" in a way that formal epistemology has yet to do. Naturalized epistemologists routinely crop up in the philosophy curricula of our universities. Formal epistemologists sometimes do, but not routinely; not in philosophy departments. This, I think, is subject to change, sooner rather than later.
}

(C) John Woods. Informal Logic, Vol. 33, No. 2 (2013), pp. 292-331. 
and "Burgessian" orientations and the tension between them the pull between a theory's "conceptual adequacy" and its "technical or formal virtuosity."

Model based reasoning has long been a staple of theorybuilding in the physical, biological and social sciences. Its presence in the philosophy of science is a more recent development. ${ }^{10}$ More so its influence on epistemology. When a model based theory has an empirical subject matter-whether the dynamics of natural selection in populations, or the slipperiness of the freshly Zambonied ice at Madison Square Garden, or capital flows in deregulated markets - there is a deeply structured semantic fact about its models. It is that in some essential way what holds in the models fails to hold on the ground. Sometimes a theory of this kind will have a further feature which is said to explain this structural gap. When the subject matter of a theory is a human practice of a given kind $\mathrm{K}$, it is a theory of K-behaviour or a K-theory. When such a theory advances assessment standards it is a normative K-theory. For generality let's speak of $\mathcal{N}$-theories. There are, of course, more $\mathcal{N}$-theories than you can shake a stick at. To keep things manageable, I propose here to restrict their range to those that meet the following two conditions. The classes of K-event they investigate are of a broadly epistemic kind, and the methods of investigation, in a sense that will be further explained as we go along, are mathematical. So we should think of our reflections as a general sort of commentary on formal epistemology, especially its Bayesian variations. ${ }^{11}$ To that end, I want to tarry awhile with the three questions:

\footnotetext{
${ }^{9}$ To be clear: The historical Burgess is not himself a radically inflexible Burgessian. The same is true for van Benthem's own Benthemitism.

${ }^{10}$ The use of models in mathematics and logic has a more settled and stateable history. See, for example, Badesa (2004) and Hodges (2007). As far as I know, comparable survey works for models in science have yet to be written.

11 Here, too, expository convenience calls for a certain generalized latitude. There is scarcely a principle of any importance that Bayesians in the flesh don't disagree about.
}

(C) John Woods. Informal Logic, Vol. 33, No. 2 (2013), pp. 292-331. 
1. To what extent is it incumbent on a $\mathcal{N}$ to heed the ins-andouts of K-behaviour on the ground, and how is this done?

2. How should a $\mathcal{N}$ of K-behaviour balance (if at all) analytical elucidation of its target concept - the concept of $\mathrm{K}$ - with the requirement that $\mathcal{N}$ be a mathematically well-made theory?

3. What is the source of $\mathcal{N}$ 's normative legitimacy, and how does the $\mathcal{N}$-theorist have access to it?

\section{Concerning question (1)}

Question (1) asks for the extent to which it is incumbent on a theory of the assessable K-practices of human beings to heed the insand-outs of K-events as they actually occur. Among philosophers of broadly analytic persuasion there is sizeable support for the idea that part of the answer has to do with the recognizability of a theory's subject matter. Even at high levels of mathematical complexity, a good many $\mathcal{N}$-theories are influenced by a simple principle of Burgessian import:

CONCEPTUAL RECOGNIZABILITY: Whatever its other features, a $\mathcal{N}$-theory of $K$ should try to make the concept of $K$-events or K-practice recognizably present in its theorems.

So constrained, a mathematical theory of a subject matter K which, except for the theory's tutelage no one in his right mind would recognize as an account of K-behaviour, would be a K-theory in name only.

Most logicians will be aware of a dispute between dialethic and non-dialethic approaches to true contradictions, with Quine making an unrecognizability charge and Priest (among others) resisting it. ${ }^{12}$ Quine's complaint was that in allowing for the truth of

\footnotetext{
12 A small grammatical point: The coiners of the term spell it "dialetheic" (similarly "dialetheism"). Nothing in the grammar of either Greek or English justifies

(C) John Woods. Informal Logic, Vol. 33, No. 2 (2013), pp. 292-331.
} 
certain select statements of the form $\left.{ }^{\ulcorner} \mathrm{A} \wedge \sim \mathrm{A}\right\urcorner$, dialetheists had made the concept of negation unrecognizable. Quine's complaint is an especially strong one. He thinks that even with the tutelage offered up by dialethic logicians, any allowance for a true contradiction obliterates the very idea of "not." Without trying to settle that matter here, there is value in mentioning it. It brings to the fore the conceptual recognizability condition on theories. ${ }^{13}$ It invites us to ask whether, all things considered, this is a plausible constraint. It bids us consider how Burgessian we should want to be.

\section{Concerning question (2)}

Question (2) is tightly connected to the issues raised by question (1). It asks whether a solid basis exists for determining a correct balance between a theory's mathematical virtuosity and its conceptual clarity. Consider a $\mathcal{N}$ that gets the facts on the ground wrong, that is, wrong on purpose. Suppose again that $\mathcal{N}$ is a logic of premiss-conclusion reasoning or rational decision-making. Suppose that it decrees that a rational agent is one who closes his beliefs under consequence and takes his decisions on the basis of perfect information. Of course, these are stipulations massively defected from in actual practice. If we persisted with them, we would encumber ourselves with a passing strange notion of rationality. If our logic allowed that an agent is rational to the extent that he revises his be-

the second occurrence of 'e.' "Aletheia" gives us "alethic." Why wouldn't "dialetheia" give us "dialethic"?

${ }^{13}$ For Quine's complaint see Quine (1970/1986), p. 81, and for a reply see Priest (1999). A further recognizability dispute arises from the Routley star semantics for first degree entailment (FDE). Here too negation is the issue. Star worlds lack an intuitive characterization. Every world has a unique star world, and the star world of the star world of a given world is that same given world. In the event that a world has itself as its star world, negation has a classical structure. Otherwise, a sentence ${ }^{\ulcorner} \sim \mathrm{A}^{\urcorner}$is true in $w$ just in case $\mathrm{A}$ is false, not in $\mathrm{w}$, but rather in its star world $\mathrm{w}^{*}$. Informally, ' $\sim \mathrm{A}^{\urcorner}$is true in this world if and only if $A$ 's falsity is possible here. For a discussion of the unrecognizability wrinkles occasioned by this treatment of "not," see Restall (1999) and Woods (2012).

(C) John Woods. Informal Logic, Vol. 33, No. 2 (2013), pp. 292-331. 


\section{John Woods}

liefs and makes his decisions in accordance with this logic, then its take on human rationality could only be that rationality is precisely what human beings lack under precisely those circumstances in which the rest of us in our untutored moments would think it not lacking at all. Many of us, philosophers and others alike, would be of the view that any logic of reasoning and decision-making that made all of us sweepingly and systematically irrational is a logic guilty of distortion on a scale that qualifies as conceptual misanalysis. In shorter words, any such logic would sanction theorems whose falsity is a matter of conceptual necessity. They are theorems that a Burgessian would have us reject.

I have asked whether the K-recognizability condition is a plausible requirement for $\mathcal{N}$-theories. The answer presently at hand is in the affirmative: The theorems that make K-hood unrecognizable are false as a matter of conceptual necessity. A doubter might demand to know why this would matter? The answer is that it would matter if a certain very influential appreciation of normative $\mathrm{K}$-theories were true. It would matter if a theory's role were to provide a conceptual analysis of $\mathrm{K}$. If so,

CONCEPTUAL MISANALYSIS: $\mathcal{N}$-theories that make their target Ks unrecognizable misanalyze those Ks and, in so doing, fail the conceptual adequacy condition on theories.

COROLLARY: Given a Burgessian orientation, such theories should be rejected.

The conceptual recognizability constraint doesn't lack for critics. Those who like it tend to give to "our" pretheoretic intuitions a load-bearing role in philosophy. Experimental philosophers aren't so sure, and the same can be said for rational reconstructionists of reductive stripe. ${ }^{14}$ Then, too, there are philosophers who demand

\footnotetext{
${ }^{14}$ See in the first instance Knobe and Nicols (2008), and in the second Carnap (1928/1967).

(C) John Woods. Informal Logic, Vol. 33, No. 2 (2013), pp. 292-331.
} 
recognizability in one kind of intellectual context and yet are quite happy to do without it otherwise. ${ }^{15}$

It is a fact of some importance that not every $\mathcal{N}$ with an empirically instantiated subject matter whose theorems are false on the ground makes its subject matter unrecognizable. Some such theories have theorems that are approximately true to what actually happened, hence might plausibly be said to be theories that make their target properties somewhat recognizable or quasirecognizable. So the distinction between having and lacking empirically false theorems does not map theories to the distinction between those failing and those meeting the condition of $\mathrm{K}$ recognizability. Even so, we should also be careful not to lose sight of the fact that not every empirically false theorem is approximated to thus. For example, as we've seen, the axiom by which belief is closed under consequence is infinitely unapproachable by the inferences of real life. I'll come back to this in section 12 .

\section{Empirical sensitivity}

Empirically instantiable model based theories are empirically sensitive:

EMPIRICAL SENSITIVITY: An empirically sensitive model based theory of an empirically instantiated subject matter is one that pays principled attention to empirical deviations from its theorems. Attention is principled when it includes a determination of whether or not the empirical discomportments overturn the theory or require some amendment of it.

Of course, the same is true of model based theories of all kinds, not just the normative ones. Accordingly, we might propose that a

\footnotetext{
${ }^{15}$ Quine again comes to mind. Quine demands it for logic. He rejects it for physics where among other things, "a body is now a class of quadruples of sets of numbers according to an arbitrarily adopted system of coordinates. We are left with just the ontology of pure set theory" (Quine, 1981, p. 17).
}

(C) John Woods. Informal Logic, Vol. 33, No. 2 (2013), pp. 292-331. 


\section{John Woods}

good way for any model based theory with empirically false theorems to preserve the recognizability of its subject matter is to advance those theorems with empirical sensitivity. It is more easily said then done.

There are two main forms that theory's empirical sensitivity might take. The theory might recognize the data on the ground as having the force of counterexamples, and seek to amend itself accordingly. Or it might take the normative high ground and resolve the conflict by negative assessment of deviant behaviour on terra firma. Both these options are affixers of blame. The first blames the conflict on the theory. The second blames it on practitioners.

There are problems with these approaches. If the theory is a theory of assessable human behaviour, the first option of holding its feet to the fires of empirical fact raises difficulties of its own. One is that the restoration of empirical fidelity often-times erodes the theory's formal elegance and derivational power. In plainer words, empirical fidelity may cost a theory some of its most prized theorems. (A somewhat Benthemite note.) So there is a tension between technical adequacy and empirical fidelity, to which any rapprochement between formal and informal approaches to such theories must pay heed. The second option of ganging up on noncompliant practitioners for falling short of what $\mathcal{N}$ demands of them raises question (3), which will occupy us just below.

\section{Concerning question (3)}

Question (3) returns us to the problem of normativity. It is directed to theories embodying normative presumptions about good and bad practice. Where, it asks, is the source of the theory's normative authority, and how does the theorist have access to it? This we might call the normative authentication problem. A commonplace example of a normatively presumptuous theory is logic. It used to be widely assumed and still is, more's the pity, that a piece of reasoning is discredited if it violates a logical law. Simple inspection reveals that most of what is ordinarily taken to be good reasoning on

(C) John Woods. Informal Logic, Vol. 33, No. 2 (2013), pp. 292-331. 
the ground is invalid in the logician's sense. ${ }^{16}$ But, if the blame lies with the practitioner, not the theory, this raises a good and necessary question. What, if not getting the facts on the ground wrong, would discredit a theory? A second question lies closely by. It is a question posed by the rampant pluralism that has overtaken logic. ${ }^{17}$ If two logics disagree on a logical principle or a rule of inference, how, if at all, is the conflict resolved? A not uncommon answer involves the system relativities embodied in Carnap's Principle of Tolerance:

In Logic, there are no morals. Everyone is at liberty to build his own logic, i.e., his own form of language, as he wishes. (Carnap 1937, p. 52)

Any one system is just as good a logic as any other, no matter how incompatible. There is no fact of the matter about whether this or that is a theorem or whether thus or so is a valid rule. Something is a law of logic only relative to the system that proclaims it so.

There is much to dislike about the system relativity manoeuvre. ${ }^{18}$ I will mention just one bit of it. ${ }^{19}$ The system relativity approach to a logic robs it of the normative authority to call the shots for practices on the ground. If there were no fact of the matter about whether an argument is valid there could be no fact of the matter as to whether an argument on the ground is good or bad by way of invalidity. It is true that logicians of relativist inclination are favourably disposed toward relativized normativities, reflected in judgements of the form "That argument is bad modulo the norms

\footnotetext{
${ }^{16}$ Even if, as is often the case, the validity requirement is relaxed to include the inductive strength requirement, most of what is taken to be good reasoning doesn't meet it either. The exacting regulae of the statistico-experimental sciences are in the general case too much for the individual human reasoner to handle. See here Woods (2013).

17 Woods (2001), (2003), Beall and Restall (2006), Field (2009) and Woods (2011).

${ }^{18}$ See, for example, Siegel (1987), a classic.

${ }^{19}$ Other reservations about the theorists' privileged access to normative authority are discussed in Gabbay and Woods (2003b).
}

(C) John Woods. Informal Logic, Vol. 33, No. 2 (2013), pp. 292-331. 


\section{John Woods}

of system $S$." But as long as they remain system relativists about logic, there is no way that logic gives us to close the gap between "bad in $S$ " and "bad." So either a judgement of "bad" is unsupported by a supportable judgement of "bad in $S$," or it is supportable, but not by logic. Either way, an argument's goodness or badness cannot be determined by logic. It is determined, if at all, by the non-logical decision to adopt this logic rather than that one. The normative authentication problem is left untouched.

It is sometimes supposed that a theory's K-norms are validated when they stand in a relation of reflective equilibrium to settled $\mathrm{K}$-practice. According to some $\mathcal{N}$-theorists, it is the sort of balance that is achieved when "the model may correct our intuitions and make them more precise" or "our intuitions may suggest a correction of a philosophical model" (Hartmann 2009, p. 23). The critical factor here is the scope of "our." If the "our" of our intuitions is all of us, then the last thing that can be said of the idealizations of formal epistemology is that they are in reflective equilibrium with our cognitive practices. On the other hand, if the "our" of our intuitions is some or other self-selected group of formal epistemologists, then the old question recurs: How in the world did it get to be the case that they, of all people, were the very ones to achieve command of these insights?

Howard Raiffa is a founder of rational decision theory (Raiffa 1968). George Kennan was the US State Department's chief architect of the Cold War doctrine of containment, one of whose pillars was the Marshall Plan (Kennan 1985). The containment strategy was a brilliant success and Kennan's decisions were of farreaching importance. But Kennan's decisions routinely fell short of the Raiffa norms. For one thing, in all his long life George Kennan never once closed his beliefs under consequence. Never in his long life did he get finitely close to perfect information. Who, in some apt children's words, made Howard Raiffa king of the castle? ${ }^{20}$

\footnotetext{
${ }^{20}$ There is an amusing story about Raiffa, perhaps too good to be true, but told as true by Paul Thagard in a lecture given at Sestri Levante to the MBR-12 Conference on Model Based Reasoning in June 2012. When Raiffa was at Columbia he
}

(C) John Woods. Informal Logic, Vol. 33, No. 2 (2013), pp. 292-331. 
Left undealt with the normative authentication problem for $\mathcal{N}$-theories is a standing embarrassment and, some would say, a deal-breaker.

\section{Transfinitely false idealizations}

Model based science is chock-a-block with devices that deliver deliberate and benignly intended distortions of what happens on the ground. Leading the list of distorters are idealizations, which assert as true what is false on the ground - think here of perfectly rigid rods and infinitely large populations - and abstractions, which suppress as unimportant what is true on the ground - think here of the scalene triangle. Some idealizations are limits to which the facts on ground approach in some finite degree. But some are not in the least approachable. In population genetics, populations are infinitely large. The smallest actual population and the largest actual population are equally far removed from the ideal, namely infinitely so. In neoclassical economics, utilities are infinitely divisible, leaving the smallest pleasures of real life infinitely less divided than the model's ideals. The same again is true of the closure law for beliefs. If beliefs were indeed closed under consequence, then the cardinality of the conclusions an actual agent infers from anything he believes must fall infinitely short of the cardinality of the conclusions the ideal agent draws. ${ }^{21}$ Idealizations of this sort are not

received an offer from Berkeley and was having a difficult time making up his mind. Having become aware of this quandary, Raiffa's colleague Ernest Nagel proposed that the relevant facts be plugged into Raiffa's own decision-model, the button pressed, and the right answer patiently awaited. "Come on, Nagel," the agitated Raiffa replied, "this is serious!"

${ }^{21}$ Perhaps it will be suggested that a finitely unattainable limit sanctions a notion of finitely attainable greater and lesser degrees of approachability. Thus, we might find ourselves wanting to say that of the consequences you draw from A outnumber the consequences I draw from it, then, although neither of us approximates the consequence-drawing in any finite degree, you approach the limit more robustly than I. My view of this is that it doesn't help much with the point at hand. If approachability in the present sense is allowed to displace approxima-

(C) John Woods. Informal Logic, Vol. 33, No. 2 (2013), pp. 292-331. 


\section{John Woods}

only not quite untrue empirically. They are utterly untrue empirically. They are as we said, infinitely unapproachable or, as we might also say, transfinitely false. They are propositions that approximate to truth in no finite degree. ${ }^{22}$

We come back to the point that a scientific theory that relies in any essential way on distortions such as these is expected to pay for them at the empirical checkout counter. But not all empirically distorting theories are capable of, much less designed for, such negotiations. If a theory is not designed for empirical payoff, and yet transfinitely distorts what happens on the ground, what justifies this cost? One answer of course, is its normative rather empirical payoff. But this runs us head-long into the as yet unsolved normative authentication problem.

Another response to the gap-problem is the theory's technical virtuosity. It is an answer according to which a theory may get the facts on the ground wrong, it may lack a persuasive normative authority, and it may be guilty of conceptual mismanagement, but by golly, it's a lovely piece of mathematics! Which brings us back to question (2), and the Benthemite idea of "playing around" with "new wave[s] of free speculation."

\section{More about question (2)}

bility, it still remains that, for any given number of consequences drawn, it is always more rational to draw a greater number of them than that. While we're on this point, much the same reservations can be directed to suboptimality theories which seek to reduce the severity of maximizing ideals by replacing them with gentler alternatives. Various efforts to lighten up, in the one case by fuzzifying probability measures and in the other by relaxing the strictness of Bayesian standards are well-discussed in the literature. See in the first instance Jeffrey (1984), van Fraassen (1990), and in the second van Fraassen (1984), (1999). My view of the lightening up movement is twofold. It doesn't go far enough, and it claims a normative legitimacy it fails to establish.

${ }^{22}$ Transfinitely false models are discussed in Woods (2013b). See also Woods and Rosales (2010).

(C) John Woods. Informal Logic, Vol. 33, No. 2 (2013), pp. 292-331. 
Here is an example of the contrast between a theory's conceptual and mathematical adequacy. It is drawn from Bayesian epistemology. Bayesians differentiate their approach from traditional epistemology, which proceeds by an examination of epistemic intuitions and the concepts embedded therein. Since the traditional epistemologist is typically a proponent of conceptual analysis, he will have some sympathy for the concept-recog-nizability requirement. Bayesians have a different motivation. In the words of two of its able practitioners, "Bayesian epistemology, on the other hand, draws much of its power from the mathematical machinery of probability theory" (Hartmann and Sprenger 2011, p. 619). This approach to epistemology

starts with mathematical intuition. The construction of Bayesian models is much triggered by what is mathematically elegant and feasible (e.g. Spirets et al. 2001). The mathematics develops a life of its own (to adopt a phrase due to Hacking), and the comparison with intuitive examples comes only after the Bayesian account is given (Hartmann and Sprenger 2011, p. 619; emphases in the original). .... Indeed it is easy to distort the problem under consideration by making implausible assumptions that make the modeling easier (Bovens and Hartmann 2003, p. 130).

We have arrived at a critical juncture. I said earlier that the mathematicization of a non-mathematical subject matter counts as extreme to the extent to which its mathematical provisions infiltrate that subject matter. Bayesianism, as here described, is mathematicized epistemology of high order.

Of course Bayesians don't think of themselves as wholly indifferent to the conceptual implausibilities occasioned by their models. Theirs is not the Anything Goes line in epistemology. In fact,

... it is often all too easy to get carried away by the formulae. Not every partial derivative is meaningful-no matter how pretty the result. (Bovens and Hartmann 2003, p. 130)

(C) John Woods. Informal Logic, Vol. 33, No. 2 (2013), pp. 292-331. 
However, as Hartmann and Sprenger also insist, the "Bayesian framework is very convenient for" the study of the intuitive data, owing in no small measure to the fact, as they suppose, that "it comes with principles that can be made plausible on rational grounds (Dutch Book arguments, Principal Principle, Bayesian Conditionalization)" (Hartmann and Sprenger 2011, p. 619; emphasis in the original). ${ }^{23}$

Note that this attention to "intuitive data" comes after the theory's mathematical intuitions are catered for. Once the theory is up and running, the intuitive data can be brought to heel by the normative authority the mathematics is presumed to possess. Accordingly

SHEDDING INTUITIONS: The mathematical theory owes no ultimate allegiance to intuitive concepts and is fully empowered to override those intuitions when they deviate from the theory's provisions.

If anything is true of belief change on the ground it is the sheer extent to which it deviates from the axioms of the probability calculus, making of these three elements - the Dutch Book theorem, the Principal Principle and Conditionalization-largely an academic matter. Strict Bayesians will not allow that these empirical deviations in any way discredit the principles. For they are mandated and made impervious to this kind of empirical discouragement "on rational grounds," that is, by the normative authority to regulate the concept of rationality in this way. But this just cycles us back to where we were only paragraphs ago, where it was proposed that the

\footnotetext{
${ }^{23}$ Informally, the Dutch Book theorem holds that it is irrational to shape the degrees of one's beliefs in ways that deviate from the axioms of the probability calculus. The Principal Principle holds that if an agent knows the objective probability of a proposition $A$ to be $p$ and has no information to the contrary, then his rational degrees of belief in $A$ must also be equal to $p$. Bayesian Conditionalization asserts that the rational degree of belief in a proposition $A$ after learning $E$ is the conditional probability of $A$ given $E$.
}

(C) John Woods. Informal Logic, Vol. 33, No. 2 (2013), pp. 292-331. 
approved way to go is simply to calumniate standard practice for its deviations from the theory's normative presumptions.

My own view is that Bayesians - indeed virtually all the going formalizers of human cognitive practice - are confused about the factors that confer normative authority on their theories. To explain this further, we would do well to give some thought to a pair of very old ideas in epistemology. One is that a normative theory cannot be upset by empirical facts. The other is that a mathematical theory is likewise impervious to empirical confutation. ${ }^{24}$ As we see from Hartmann's and Sprenger's remarks just now, Bayesians are drawn to an assumption to which, so far as I can tell, they have yet to give voice:

MATHEMATICIZING NORMATIVITY: The central reason why $\mathcal{N}$-theories can't be overturned by recalcitrant experience is that since $\mathcal{N}$-theories are mathematical theories, their normative authority derives from that same mathematical imperviousness to those discomportments.

In so saying, we have a classical many-one confusion. Mathematical theories are impervious in this way. So are normative theories. Ergo, mathematics is normative.

We might be forgiven for thinking that Bayesians are pixilated by the power and majesty of mathematics. Arguably the greatest metaphysical discovery ever made by science is the extent to which the deep regularities of nature are mathematically expressible. We might also say that one of the greatest discoveries in the epistemology of the natural sciences is that a mathematical theory of nature is capable of successful negotiation at the empirical checkout, hence capable of succeeding or failing on the strength of the observational predictions it manages to help generate. In the fullness of time, beginning with economists, social scientists set out to discern a similar link in the mental and behavioural sciences. Lately they

\footnotetext{
${ }^{24}$ Notwithstanding some significant reservations here and there. See, for example, Maddy (1997) and Bostock (2009).
}

(C) John Woods. Informal Logic, Vol. 33, No. 2 (2013), pp. 292-331. 


\section{John Woods}

have been joined by philosophers of a like tilt. It has not been a problem-free conversion.

Whole classes of mathematical theories of assessable human behaviour have risen up and flourished, undiscouraged by the recognition that, unlike physics, they cannot ground their findings or authenticate their assertions at the empirical checkout counter. Short of giving up, this leaves their proponents with a hybrid of the two alternatives that we've been examining. Normativize the theory, or mathematicize it. The hybrid marries the two in a particular way, in which, as we saw, normativization is achieved by mathematicization. This I take to be the inclination of Bayesians of the Hartmann-Sprenger stripe. For how else are we to understand their assurances that when its pronouncements conflict with the intuitive data a theory driven by mathematical intuitions will make this a tolerable shortfall "on rational grounds"?

\section{Rethinking mathematical intuitions}

Let me now pick up the threads of two sections ago. Ian Hacking's metaphor in which a theory's mathematics "takes on a life of its own" has an undeniable allure, and the extent to which it captures what actually happens in $\mathcal{N}$-theories is absolutely striking. But it is not absolutely true. It is not true in ways that precludes a $\mathcal{N}$-theorist questioning, case by case, his theory's own provisions. This can be illustrated by a brief glance at the old problem of irrelevant conjunctions. Suppose we have strong evidence that the Canuck's are playing tonight. This should not also be evidence that the Canucks are playing tonight and the Leafs will win the Stanley Cup in $2013 .{ }^{25}$ Yet without some resourceful tampering, this is precisely what the Bayesian treatment of evidence provides:

\footnotetext{
${ }^{25}$ Not everyone will know that the Canucks and the Leafs are National Hockey League teams and that the Stanley Cup goes annually to the NHL championship team.
}

(C) John Woods. Informal Logic, Vol. 33, No. 2 (2013), pp. 292-331. 
Assume that $\mathrm{E}$ is evidence for $A$ and that $\operatorname{Pr}(E \mid A . X)=$ $\operatorname{Pr}(E \mid A)$ for any sentence $X$ consistent with $A$. Then $E$ is also evidence for $\left.{ }^{\ulcorner} A \wedge X\right\urcorner$, for any measure of support. (Fitelson 2002)

The irrelevance problem has spurred a spate of attempts to reshape the conditions on evidence, prompting one philosopher to remark:

Thinking about the different measures of support suggests to me that there is no single clear cut question being asked when we ask "How much support does $P$ get from $G$ ?" It would not be surprising if the same were true of the question "How much does evidence $E$ support hypothesis $A$ ?" (Christensen 1999, p. 439)

If time permitted, it might be interesting to review with care the main candidates - see here Crupi et al. (2007) — but that is not my purpose here. My purpose here is to ask

Upon what grounds is it to be determined that a mathematical theory of belief change in which irrelevant conjunctions are derivable is bad mathematics?

And with it a second question:

If indeed such a theory is bad mathematics, what is it about the mathematics that makes it so?

There are some easy but unhelpful answers we could consider. A mathematical theory is bad if it is inconsistent. ${ }^{26} \mathrm{~A}$ mathematical theory is bad if it is lazy-e.g., some of its key assertions aren't proved. A mathematical theory is bad when it is fat-e.g., lots of its theorems are redundant. These we might think of as internal difficulties. Our interest here lies elsewhere. It concerns the external

${ }^{26}$ Or, with a nod to dialethists, it is promiscuously inconsistent. See Mortensen (1995).

(C) John Woods. Informal Logic, Vol. 33, No. 2 (2013), pp. 292-331. 


\section{John Woods}

difficulty occasioned by landing one's account of evidence in the lap of irrelevant conjunctions. Whence, then, the source of this badness?

We are thus moved to ask whether the mathematical theory of probability is mathematics. The answer, of course, is that it is not. We have but to touch on the core elements of Bayesianism to seek why this is so:

1. Beliefs are had in real valued degrees. (Philosophy)

2. Beliefs are subjective probabilities. (Philosophy)

3. Probabilities obtain in real valued degrees. (Philosophy)

4. "P" is a name-forming operation on sentences A. (Philosophy)

5. For all propositions $A$ there is a real number $x \in[0,1]$ such that $\mathrm{P}(\mathrm{A})=x$. (Philosophy)

6. $\mathrm{P}(\mathrm{A})=0.4$, and $\mathrm{P}(\mathrm{B})=0.2$, with $\mathrm{A}$ and $\mathrm{B}$ independent. (Assumed as fact)

7. $\mathrm{P}(\mathrm{A} \wedge \mathrm{B})=\mathrm{P}(\mathrm{A}) \times \mathrm{P}(\mathrm{B})$ (Philosophy)

8. $0.4 \times 0.2=.08$ (Mathematics)

9. $\mathrm{P}(\mathrm{A} \wedge \mathrm{B})=.08($ from $6,7,8)$

Thus (9) arises from the five philosophical propositions that serve a foundational role, together with an assumed fact, two more philosophical propositions and one rather measly calculation from the arithmetic of real numbers. For all the fuss that is made of the mathematical power of probability theory there is in a Bayesian appropriation of it for the purposes of epistemology hardly anything that counts as mathematics. Even so, we should not conclude that mathematics doesn't, after all, call the shots in Bayesian epistemology. Here is why. If you are one of those philosophers who think it important that a theory of knowledge recognize that belief comes in degrees, you may want to made degrees of beliefs calculably manipulable in your theory. If so, you would be well-advised to conceptualize belief in ways that allow this to happen. True, there is hardly any mathematics in Bayesian epistemology. But given the premium it puts on doxastic calculabilities it is hardly

(C) John Woods. Informal Logic, Vol. 33, No. 2 (2013), pp. 292-331. 
avoidable that the arithmetic of the reals would call some of the theory's non-mathematical shots. So we see that mathematicizing a non-mathematical concept can fall well short of making it a mathematical concept. A very little mathematics can call quite a big shot.

\section{Where's the mathematics?}

It bears repeating that the very idea that the concepts of epistemology are mathematical concepts is risible on its face, and likewise the view that probability is mathematics. The statement that beliefs are probabilities is a philosopher's claim, as is the statement that evidential support is conditionalization. The same is true of the assertion that probabilities are real numbers and that probabilities obey the real-valued Kolmogorov axioms. Probabilities may be real numbers, but nothing in analysis makes it so.

This should steel us against overstated expressions of mathematical dominance. It should get us to see that Hartmann and Sprenger have misspoken themselves in their 2011 entry in the Routledge Companion to Epistemology. A soberer appreciation of this dominance is to be found in other of Hartmann's writings, notably in "Modeling in philosophy of science," which is part of a tribute to Patrick Suppes for his foundational work on modelling in the philosophy of science (Hartmann 2008) ${ }^{27}$ It is unnecessary to review this paper at any length to get out of it the points that matter for our present question. So I shall be selective in my pickings.

NOT MATHEMATICS: Bayesianism is not a mathematical theory. It began its life as a philosophical theory of confirmation. It is a philosophical theory that makes use of a mathematical theory. The mathematical theory is a theory of degrees or amounts of confirmation. For example, the equation of evidential support with conditional probability is a philo-

${ }^{27}$ See also Suppes (1962) and (2002).

(C) John Woods. Informal Logic, Vol. 33, No. 2 (2013), pp. 292-331. 


\section{John Woods}

sophical assertion. The equation of conditional probabilities with the right-hand side of Bayes' theorem is a mathematical assertion. $^{28}$

DYNAMIC VARIATIONS: As its influence spread, Bayesianism migrated to epistemology's further precincts, and in due course coverage extended to belief change, decisionmaking, and theory change, with a concomitant shift from synchronic to diachronic analyses-hence, belief change. These, too, are philosophical developments, and they too contain mathematical mechanisms for the regulation of such quantitative factors as enter into the operation of these dynamisms. $^{29}$

NORMATIVIVELY INTENTED: Contrary to the dominance of mathematical intuitions thesis, Bayesianism's philosophical provisions are forwarded with epistemically normative intent, and virtually without independent justification. In particular, it is not expressly envisaged that they admit of mathematical authentication. Even so, that a set of philosophical propositions would admit of - indeed would welcomefruitful mathematical engagement is often take as philosophi-

28 "Bayesianism [is] a normative philosophical theory .... Bayesianism formulates constraints on the beliefs of a scientist" (p. 15). Bayesianism is also "a quantitative confirmation theory .... While qualitative [philosophical] theories formulate criteria that inform us whether or not a piece of evidence $\mathrm{E}$ confirms a hypothesis $\mathrm{H}$, quantitative [mathematical] theories of confirmation also tell us how much E confirms $\mathrm{H}$ (pp. 5-6). "But how are probabilities updated? .... There is a lot of debate about this question amongst Bayesians and there is clearly no consensus. Many, however, hold that the new probability measure should be the conditionalized old probability measure. I'll not defend this choice, but will use it in the remainder [of this paper]. Note, however, that this choice is not dictated by mathematics. What is dictated by mathematics is how one evaluates the expression on the right side ..." (pp. 5-6). Actually, as we saw, not even this is true. There is nothing in real analysis that tells us this. Bayes' theorem is not a theorem of mathematics. It is a philosopher's thesis.

${ }^{29}$ See Bovens and Hartmann (2003), chapter 1 et passim.

(C) John Woods. Informal Logic, Vol. 33, No. 2 (2013), pp. 292-331. 
cally encouraging. This is a point of significant equivocation in formal epistemology generally. ${ }^{30}$

INTUITIONS REDUX: If pressed, however, Bayesians will concede that the normative authority of its pronouncements rests on our conceptual intuitions about the matters at hand, anyhow those of them that are currently in reflective equilibrium.

Here is Hartmann himself on the last two of these points:

Why should we believe in a philosophical model, accept its consequences and be content with an explanation that a philosophical model provides us with? After all, unlike science, we cannot compare the model with "hard" data from experiments. All we have in philosophy is our intuitions, and all we can do is to aim at a reflexive [sic] equilibrium between our intuitions and the consequences of the model .... Clearly, much more needs to be said about the assessment of philosophical models, but I have to leave this for another occasion. (pp. 22-23)

And here is a further word (from me) about reflective equilibrium. I have already observed that what standard cognitive practice is not in reflective equilibrium with are the normatively presumptive ideals of Bayesian epistemology. Still, I agree that our business-asusual cognitive practices probably are in reflective equilibrium with the actual norms, whatever they chance to be.

Let's be clear, then. Bayesians don't identify epistemic objects and properties with mathematical objects and properties. What they do is represent epistemic objects and properties as mathematical objects and properties. They do so, it is said, for the benefits that redound from this way of proceeding to the objects

\footnotetext{
${ }^{30}$ When neoclassical economics introduced the infinite divisibility idealization for utilities, it is easy to say why. It was done to enable economics to engage the mathematical fire-power of calculus.
}

(C) John Woods. Informal Logic, Vol. 33, No. 2 (2013), pp. 292-331. 


\section{John Woods}

and properties of epistemology. But what benefits? And how are they realized?

\section{Representation}

The word 'representation' carries more meanings in philosophy than it can comfortably wear. There is a lifetime's work, and then some, in bringing this idea to philosophical heel. My purpose in invoking it here is the occasion it gives briefly to consider one of the ways in which we might treat a well-known difficulty that attends it. Representations are routinely called upon to remove the sting of false identifications. If someone says that beliefs are probabilities, he has made a false identification. If he says that probabilities are real numbers, he has made a false identification. If he says that person's confidence in a belief are the odds he is prepared to accept in a contrary bet, that too is false. If someone says that for each real number in the unit interval there is a belief whose intensity it is, this is a further falsehood. Consider the case in which, having himself advanced these claims, a theorist of Bayesian sympathies is now prepared to grant their falsity. Suppose, even so, he remains drawn to these propositions, and is reluctant to give them up. Suppose he looks for a way of neutering their alienation from the facts of standard practice. He says: Yes, strictly speaking, beliefs aren't probabilities (etc.), but it is nonetheless illuminating or instructive to represent these things as those things. It is illuminating and instructive because, in thinking of these things as those things, we attain a better appreciation of these (or other) things than would otherwise be so.

Of course, this is modelling talk of a kind that routinely attends a scientist's handling of natural phenomena. It fits especially well the notion of "phenomenological" model, typified by Bohr's planetary model of the interior of the atom. Bohr's contention was that thinking of quantum phenomena in that way was helpful in understanding the notion of quantum leap. Bohr was right. It did help.

(C) John Woods. Informal Logic, Vol. 33, No. 2 (2013), pp. 292-331. 
Representation is not FOB. There are excise duties to be paid. A representation of something would be of little moment if the way it got you to think of it made no contribution to your theory's success. We have it by construction of the case that although electrons aren't planets, it is illuminating to think of them that way. But this is unavailing if thinking of them in that way makes no advance at the checkout counter. Needless to say, no one thinks that that the planetary representation is a nonredundant premiss in the derivations that yield the observational predictions of quantum theory. But I am prepared to concede - if only for the sake of argument and to speed things up - that Bohr's representation may have played a causally efficacious role in the thinking up of the premisses that $d o$ figure in those derivations.

In like manner, I am prepared to grant-with the same qualifications - that giving to the central concepts of epistemology Bayesian representations may in some distant future prove causally efficacious in finding new premisses for epistemology that some of us may come to like better than the ones we've got now. But what we shouldn't concede is that the new premisses and the conclusions they link up with will vindicate the representations in the way that we are supposing for quantum theory. It is all down to the same old grief. Quantum theory has a future at the empirical checkout stand. Bayesian epistemology, on its own conception of itself, does not. This is a yawning difference. On present assumptions, the Bohr representation pays its taxes by virtue of the causal provocation it lends to the thinking up of a scientific theory that does well at the checkout counter. The Bayesian representations might be said to pay their taxes by virtue of the causal provocations they lend to the thinking up a theory of knowledge that Bayesians like better than the old one. That Bayesians take a liking to their own norms makes no dent on standard practice (not even their own). So the empirical deviation problem remains a problem unless Bayesians can find a more convincing way to solve the normative authentication problem. The normative legitimacy problem is left unsolved. Considerations on an empirically accessible normativity are worked up in

(c) John Woods. Informal Logic, Vol. 33, No. 2 (2013), pp. 292-331. 


\section{John Woods}

chapter 2 of my Errors of Reasoning: Naturalizing the Logic of Inference (Woods 2013a). Here, very briefly, is its gist.

In epistemology's analytic/formalist orientations good practice is a matter of conformity to the requisite criteria of goodness. The criteria could be considered as rules/programs, and conformity would be seen as a kind of obedience/imple-mentation. The naturalistic perspective is different. The goodness of practice is not a matter of obedience to rules or implementation of programs, whose purport is to define the meaning of "good practice (of that kind)." A piece of reasoning-behaviour is good when the causal mechanisms which produced it are in apple-pie working-order and are operating here as they should. Thus reasoning well is more like breathing well than shaping and restraining one's behaviour in direct response to the Ten Commandments (whether from Heaven or Amsterdam). So far as is known empirically, the cognitive equipment of beings like us is in good working-order and operating the way it is supposed to pretty much as a matter of course. Not always, to be sure, but enough of the time to ground a judgement of "normally." In which case, we might want to seize on this and proclaim

The NN-Convergence Thesis: In the absence of countervailing considerations, in matters of human reasoning what normally happens is what should happen. In other words, the normative converges on the normal.

I present NN Convergence to give notice of it, but not with any present expectation that it will quiet the normative anxieties of people with non-naturalistic leanings. It's a gander-goose matter. I don't like the nonnaturalist's treatment of normativity. Very well, shouldn't I be expected to do better? Shouldn't, at least, I be prepared to expose my own view to the critical eye of the other side? Yes, of course. But that question doesn't have to be settled here. Mathematicized epistemology stands or falls independently of the fate of NN-Convergence.

(C) John Woods. Informal Logic, Vol. 33, No. 2 (2013), pp. 292-331. 


\section{Mathematicization as synthesis}

When formal methods are applied to a concept, they constitute a formalization of it. When formal methods have a substantial mathematical character, they constitute a mathematicization of the concept. When speaking of a concept's meaning in pre-formalized linguistic practice, let us say that we are speaking of its intuitive meaning or, equivalently, of the intuitive concept. Consider now our earlier question, "What is achieved by the mathematicization of a concept; for example, what do we learn about knowledge from a mathematicization of the concept of knowledge?" At the appropriate level of generality, there are four different answers to this concept-capture question.

Analysis The mathematicization of concept K explicitizes the meaning it has in pre-formalization linguistic practice; that is, it captures K's intuitive meaning. ${ }^{31}$

Explication The mathematicization of a concept $\mathrm{K}$ preserves its pretheoretical meaning but does so in ways that gives to $\mathrm{K}$ a more aggressive clarity than it has in pretheoretical linguistic practice.

Rational reconstruction The mathematicization of a concept $\mathrm{K}$ involves an additional attribution to $\mathrm{K}$ of features not present in pretheoretic linguistic usage, but in a manner that retains enough of the intuitive concept to make it intelligible to say that its rational construction is a formalization of $i t$, rather than some other.

\footnotetext{
${ }^{31}$ For lack of space, I pass over two important variations of the definitional condition on formalization, namely, implicit definitions and contextually eliminating ones. For the first, think of the definition of the concept of number afforded by the axioms of number theory. For the second, think of the reduction of number theory to set theory attempted by Frege and Russell.
}

(C) John Woods. Informal Logic, Vol. 33, No. 2 (2013), pp. 292-331. 


\section{John Woods}

Stipulation Here the mathematicization constitutes a nominal definition of a concept lacking a prior presence in pretheoretical linguistic practice.

The distinction between analysis and stipulation is roughly Kant's contrast between analysis and synthesis. Analysis, says Kant, is the business of making concepts clear, and synthesis the business of making clear concepts. Analysis is the purview of philosophy, and synthesis the province of mathematics. ${ }^{32}$ In this taxonomy, explication and rational reconstruction are hybrids, with explication more analysis-like and rational reconstruction trending towards stipulation. Similarly, analysis is the most Burgessian option, and stipulation the most Benthemite. Explications and rational reconstructions are likewise hybrids, with explication tilting more to the Burgessian and reconstructions more to the Benthemite.

There are, of course, grey areas at each of these borders. As Quine once quipped, one person's explication is another's stipulation. But there are some reasonably clear examples. Philosophers in the tradition of Moore think that the correct analysis of the concept of material thing is inconsistent with (subjective) idealism. Mathematicians take the view that the axioms of plane geometry offer an explication of the intuitive concept of physical space. The notion of rational reconstruction we associate with Carnap. Its presence may be felt in Carnap's attempt to formalize physical objects as logical constructions of sense data. Stipulation is the stock and trade of mathematics, as Kant noted. But it is also solidly at work in all of model based science. Populations are infinitely large; utilities are infinitely divisible; belief is closed under consequence; and deciders have perfect information. The analysis of a concept presupposes its intuitive presence in preanalytic practice. It requires full recognizability. An analysis may be said to be conceptually faithful to the degree that it preserves the presence of its intuitive analysandum. At the other end of the spectrum, synthesis, or the stipulation of new concepts, places a premium on the clarity

${ }^{32}$ Kant (1764/1974) and (1800/1974).

(C) John Woods. Informal Logic, Vol. 33, No. 2 (2013), pp. 292-331. 
that can be got from an inventive mathematical virtuosity. As regards the present concept engagement possibilities, it would appear that the formalizations effected by retrofitted logics fall oftener than not in the ambit of partial reconceptualization - hence of quasi-recognizability. It is well to emphasize, however, that option four - the most creative of them all-will in principle tolerate elements of the three prior grades of conceptual engagement.

SHEDDING INTUITIONS (AGAIN): The single most distinctive feature of synthetic theories (as we may now call them) is their freedom in principle from any requirement of prior conceptual recognizability, and with it their liberation from the travails of conceptual analysis-full-blown or partial, it doesn't matter. ${ }^{33}$

While the idea of synthetic theories has its roots in Kant, it is to Carnap that we can turn for its instrumentalist justification. Any logic will do if it adequately fits our nonlogical purposes. A like permissiveness is advanced by Quine, though in mathematics, not logic, under the heading of legislative postulation. Quine's nervousness about logic is anomalous, and in any event not catered for by his own pragmatism. Be that as it may, the idea of legislative postulation carries a lot of weight here. It provides that when one postulates legislatively, there are sentences that one makes true, and via the mechanisms of quantification, makes objects one makes to exist.

Perhaps the best known example of a stipulative theory with a happy ending is Riemannian geometry. No one, least of all its inventor, took Riemannian geometry as a description of the actual

\footnotetext{
${ }^{33}$ Thus a mathematical physicist wants to prove theorems about $\mathrm{c}^{*}$ algebras in ever more general and robust settings. A theoretical physicist uses $\mathrm{c}^{*}$ algebras for improved representations of physical systems that will eventually do well at the empirical checkout counter. Similarly, a mathematical biologist tracks generalized solutions of Lotka-Volterra systems of idealized competitors. A theoretical biologist investigates biologically meaningful conditions for the coevolutionary stability of competition.
}

(C) John Woods. Informal Logic, Vol. 33, No. 2 (2013), pp. 292-331. 


\section{John Woods}

space of the physical world. Its virtues were technical, notably its proof of relative consistency. It was a significant piece of mathematical virtuosity but hardly up to the burdens of conceptual fidelity. Riemann's was not a semantic analysis of the concept space. But with the arrival of general relativity theory, it emerges that Riemann's space is the empirically well confirmed description of big space.

There is no reason to think that Riemann himself anticipated this Einsteinean application of his abstract theory. Even so, nonEuclidean geometry was ready to hand-on the shelf, so to speak - and was available for Einstein's later appropriation. But this couldn't have happened in the first place had it not been for the impressive technical virtuosity of Riemann's achievement. People would not have paid attention to it otherwise. ${ }^{34}$

Modern logic makes indispensable use of mathematics. The methods of mathematics are embedded in the generative grammars of its formal languages and they drive its theories of proof and truth, and power the techniques of their linking metatheories. Logic, of course, is not mathematics. The conjunction operator is undefined for arithmetic. But logic has got some mathematics in it. It is not wrong to speak of modern logic as mathematical. We have in this a critical distinction. It is the distinction between subject matter and method.

Bayesian epistemology should be judged in the light of these contrasts. It is a mathematical epistemology in the sense in which mathematical physics is mathematical. It is a synthetic theory, also in the way that Kant and Quine say mathematics is. Bayesian epistemology is not conceptual analysis. Bayesian epistemology creates

\footnotetext{
${ }^{34}$ I don't want to leave the impression that Riemann was simply playing about until one day, hey presto!, the general theory of relativity popped into view. Riemann's geometry was a formidable piece of mathematics. It generalized Gauss's work on surfaces to $n$ dimensional manifolds. When $n=3$, Riemann's geometry is the result. Riemann didn't think the 3D case described physical space or-since scaling up is a dubious assumption in physics - that it ever would prove to do so. Still, he did think it a physically possible hypothesis, hence a description of how the world might conceivably be.
}

(C) John Woods. Informal Logic, Vol. 33, No. 2 (2013), pp. 292-331. 
its own concepts, and makes true its own statements about them, graced by the entitlements of legislative postulation. Who knows what the future may bring? Who is to say that the concepts and theorems of Bayesian epistemology won't find useful roles to play in the evolution of our understanding of human cognition? Who can deny that in thinking of knowledge and belief in Bayesian ways, further good ideas might also be thought up?

Whatever the future of synthetic $\mathcal{N s}$ in philosophy, rosy or bleak as the case may be, there is a problem that they have yet to subdue. It is the problem with which we began. It is the problem of the gap between norm and practice. In its original form, it is the problem occasioned by the fact that if the theorems of the theory are true practice on the ground is bad or subpar or incompetent. Thus the pressure point of the matter was the truth or otherwise of its normative theorems. In the present situation, that is not the question. Conceived as synthetic theories, the norms of a $\mathcal{N}$ are always valid. They are true in virtue of the ways in which $\mathcal{N}$ has constructed its concepts. It may well be that behaviour on the ground is $\mathcal{N}$-bad or $\mathcal{N}$-subpar or $\mathcal{N}$-incompetent. But this leaves it wholly undetermined whether it is bad or subpar or incompetent. The normative authentication problem remains unsolved.

The respects in which we may now accept the characterization of Bayesian epistemology as mathematical-its use of mathematical methods and its legislatively postulational characterwon't make this problem go away. The same is true for $\mathcal{N}$-theories in general. Behaviour on the ground may be $\mathcal{N}$-bad. But what we want to know is whether it is bad. It would help enormously if philosophical $\mathcal{N}$-theories had a paid-up account at the normative checkout counter. Unfortunately however,

NORMATIVELY ROOTLESS: As presently conceived of, mathematical theories brim with new concepts and bristle with new truths. But they are theories with nowhere to go, and no future to achieve save for such further technical finesse that lies within the power of their creators and sanctioned by the freedom to be as clever as they like. 
Let's end this section where we began, with the last and utterly extraordinary word going to Raiffa:

If most people behaved in a manner roughly consistent with Savage's theory then the theory would gain stature as a descriptive theory but would lose a good deal of its normative importance. We do not have to teach people what comes naturally (Raiffa, 1961). ${ }^{35}$

\section{Conclusion}

I close with a forecast and an observation. The forecast is that serious forces are now gathering with hegemonic intent, with a view to subjecting IL's historical subject matters to the procedural rigours by which formal philosophy has achieved its current and future purchase in our intellectual affairs. The observation is that this is no more the right thing to do for theories of inference and argument than it has so far proved to be for theories of knowledge. What's sauce for the goose is sauce for the gander. As we have it so far, a normatively presumptive mathematicization is the wrong sauce for epistemology. Enough said. Aux barricades!

\section{A personal note}

I have had the pleasure of her acquaintanceship since I first met Trudy Govier in 1965 at the Summer Institute of Philosophy in Calgary, and have relished her scholarship in all the years that have followed. Informal logicians are more favourably inclined to applicational rather than foundational matters, with Trudy leaning the first way, and I the second. Among her many achievements is a body of work on various aspects of social policy, unbettered by an-

\footnotetext{
${ }^{35}$ The reference is to Savage (1954).
}

(C) John Woods. Informal Logic, Vol. 33, No. 2 (2013), pp. 292-331. 
ything of the same ilk done in the IL community, and ranking favourably with similar work from the other disciplines. ${ }^{36}$ This is applied informal logic with avengeance. Applications of such clout take much of the oxygen out of foundational enthusiasms. Such, I think, would be Trudy's own view of the matter. Perhaps she would be right. I can't help it. I salute her achievements in my own way.

Acknowledgements: For astute criticisms and helpful conversation about mathematization, I warmly thank Artur d'Avila Garcez, Roberta Ballarin, Howard Barringer, Johan van Benthem, Paul Bartha, John Burgess, Roger Clark, Dov Gabbay, Stephan Hartmann, Jonathan Jenkins Ichikawa, Carrie Ichikawa Jenkins, Lorenzo Magnani, Chris Mole, Alirio Rosales, Steve Savitt, Ori Simchen and Harvey Siegel. I am especially thankful to Rosales for several hours of vigorous conversion, and to Siegel for pressing me to expose something of my own views on the normative authentication problem. Thanks too, to editors Ralph Johnson and Tony Blair for their invitation to participate in IL's tribute to Trudy Govier.

\section{References}

Badesa, C. (2004). The Birth of Model Theory: Lowenheim's Theorem in the Frame of the Theory of Relatives. Princeton: Princeton University Press, 2004.

Barringer, H., Gabbay, D.M. and Woods, J. (2012a). "Temporal argumentation networks." Argumentation and Computation 2-3, 143-202.

Barringer, H., Gabbay, D.M. and Woods, J. (2012b). "Modal argumentation networks." Argumentation and Computation 2-3, 203-227.

\footnotetext{
${ }^{36}$ Govier (1997), (1998) and (2006).
}

(C) John Woods. Informal Logic, Vol. 33, No. 2 (2013), pp. 292-331. 


\section{John Woods}

Barth, E.M., and Krabbe, E.C.W. (1982). From Axiom to Dialogue: A Philosophical Study of Logics and Argumentation. Berlin and New York: de Gruyter.

Beall, J.C. and Restall, G. (2006). Logical Pluralism. Oxford: Clarendon Press.

Besnard, P. and Hunter, A. (2008). Elements of Argumentation. Cambridge, MA: MIT.

Biro, J. and Siegel, H. (2006). "Pragma-dialectics versus epistemic theories of arguing and arguments: Rivals or partners?" In P. Houtlosser and A. van Rees, (Eds.), Considering PragmaDialectics, pp. 1-10. Mahwah, NJ: Erlbaum.

Biro, J. and Siegel, H. (2011). "Argumentation, arguing and arguments." Theoria 26, 279-287.

Blair, J.A. and Johnson, R.H. (Eds.). (2011). Conductive Argument: An Overlooked Type of Defeasible Reasoning, London: College Publications.

Bostock, D. (2009). "Empiricism in the philosophy of mathematics." In A. Irvine (Ed.), Philosophy of Mathematics, pp. 157229. Amsterdam: North-Holland, 2009. A volume of D.M. Gabbay, P. Thagard and J. Woods (Eds.), Handbook of the Philosophy of Science, in 16 volumes from North-Holland.

Bovens L. and Hartmann, S. (2003). Bayesian Epistemology. New York: Oxford University Press.

Burgess, J. (1998). "Introduction to Part II." In R. Jeffrey (Ed.), Logic, Logic and Logic, pp. 135-142. Cambridge, MA: Harvard University Press.

Carnap, R. (1967). The Logical Structure of the World: Pseudoproblems in Philosophy. R.A. George, trans. Berkeley and Los Angeles: University of California Press. First published in German, in 1928.

Carnap, R. (1937). The Logical Syntax of Language. London: Kegan Paul, Trench, Trubner and Co. Originally published in 1934.

Christensen, D. (1999). "Measuring confirmation." Journal of Philosoph, 96, 437-461.

(C) John Woods. Informal Logic, Vol. 33, No. 2 (2013), pp. 292-331. 
Crupi, V., Tentore, K. and Gonzales, M. (2007). “On Bayesian measures of evidential support: Theoretical and empirical issues." Philosophy of Science 74, 229-252.

Field, H. (2009). "Pluralism in logic." Review of Symbolic Logic 2, 342-359.

Finocchiaro, M.A. (2005). Arguments About Arguments. New York: Cambridge University Press.

Finocchiaro, M.A. (2013). Meta-argumentation: An Approach to Logic and Argumentation Theory. London: College Publications.

Fitelson, B. (2002). "Putting the irrelevance back into the problem of irrelevant conjunction." Philosophy of Science 69, 611-622.

Freeman, J.B. (2005). Acceptable Premisses: An Epistemic Approach to an Informal Logic Problem. New York: Cambridge University Press.

Gabbay, D.M. and Woods, J. (2003a). Agenda Relevance: A Study in Formal Pragmatics. Volume 1 of A Practical Logic of Cognitive Systems. Amsterdam: North Holland.

Gabbay, D.M. and Woods, J. (2003b). "Normative models of rational agency." Logic Journal of the IGPL 11, 597-613.

Gabbay, D.M. and Woods, J. (2005). The Reach of Abduction: Insight and Trial. Volume 2 of A Practical logic of Cognitive Systems. Amsterdam: North Holland.

Gärdenfors, P. (1988). Knowledge in Flux-Modelling the Dynamics of Epistemic Flux. Cambridge, MA: MIT Press.

Govier, T. (1980). "Carl Wellman's Challenge and Response. Informal Logic Newsletter 2, 10-15.

Govier, T. (1997). Trust and Human Communities. Montreal and Kingston: McGill-Queens University Press.

Govier, T. (1998). Dilemmas of Truth. Ottawa: Carleton University Press.

Govier, T. (2006). Taking Wrongs Seriously. Amherst, NY: Humanity Books.

Govier, T. (2013). A Practical Study of Argument, $7^{\text {th }}$ ed. Belmont, CA: Wadsworth.

(C) John Woods. Informal Logic, Vol. 33, No. 2 (2013), pp. 292-331. 


\section{John Woods}

Hartmann, S. (2009). "Modeling in the philosophy of science." In M. Frauchiger and W.K. Essler (Eds.), Representation, Evidence, and Justification: Themes from Suppes. Frankfurt: Ontos Verlag.

Hartmann, S. and Sprenger, J. (2011). "Bayesian epistemology." In S. Bernecker and D. Pritchard (Eds.), The Routledge Companion to Epistemology, pp. 609-620. London and New York: Routledge.

Hendricks, V. (2005). Mainstream and Formal Epistemology. New York: Cambridge University Press.

Hitchcock, D. (2013), “Appeals to considerations." Informal Logic 33(2).

Hodges, W. (2007). The History of Model Theory.

http://wilfridhodges.co.uk/history07.

Johnson, R.H. (1996). The Rise of Informal Logic. Newport News, VA: Vale Press.

Johnson, R.H. (2007). "Informal logic and epistemology." Anthropology and Philosophy 8, 69-88.

Johnson, R.H. and Blair, J.A. (2006). Logical Self-Defense. New York: IDEA Press.

Kant, I. (1974a). Inquiry Concerning the Distinctness of Principles of Natural Theology and Morality, and Logic. Indianapolis: Bobbs-Merrill. First published in 1764.

Kant, I. (1974b). Logic. Indianapolis: Bobbs-Merrill. First published in 1800.

Kennan, G. (1947). "The sources of Soviet conduct." Foreign Affairs 25, 566-582.

Knobe, J. and Nichols, S. (Eds.). (2008). Experimental Philosophy. New York: Oxford University Press.

Maddy, P. (1997). Naturalism in Mathematics. Oxford: Clarendon Press.

Mortensen, C. (1995). Inconsistent Mathematics. Dordrecht: Kluwer.

Priest, G. (1999). "What not? A defence of a dialetheic theory of negation." In D.M. Gabbay and H. Wansing (Eds.), What is $\mathrm{Ne}$ gation?, pp. 101-120. Dordrecht: Kluwer.

(C) John Woods. Informal Logic, Vol. 33, No. 2 (2013), pp. 292-331. 
Quine, W.V. (1951).“Two dogmas of empiricism.” Philosophical Review 60, 20-43.

Quine, W.V. (1960). "Carnap and logical truth.” Synthese 12, 350374.

Quine, W.V. (1981). Theories and Things. Cambridge, MA: Harvard University Press.

Quine, W.V. (1986). Philosophy of Logic, $2^{\text {nd }}$ rev. ed. Cambridge, MA: Harvard University Press. First published in 1970.

Raiffa, H. (1961). "Risk, uncertainty and the Savage axioms: Comment." Quarterly Journal of Economics 75, 690-691.

Raiffa, H. (1968). Decision Analysis. New York: Addison-Wesley. Reed, C.A. and Norman, T.J. (2003). Argumentation Machines. Dordrecht: Kluwer.

Restall, G. (1997). "Negation in relevant logic: How I stopped worrying and learned to love the Routley star." In D.M. Gabbay and H. Wansing (Eds.), What is Negation?, pp. 583-596. Dordrecht: Kluwer.

Savage, L.J. (1954). The Foundations of Statistics. New York: Wiley.

Shoham, Y. and Leyton-Brown, K. (2009). Multiagent Systems: Algorithmic, Game-Theoretic, and Logical Foundations. Cambridge: Cambridge University Press.

Siegel, H. (1987). Relativism Refuted: A Critique of Contemporary Epistemological Relativism. Dordrecht: Reidel.

Siegel, H. and Biro, J. (1997). "Epistemic normativity, argumentation, and fallacies." Argumentation 11, 277-292.

Suppes, P. (1962). "Models of data." In E. Nagel, P. Suppes and A. Tarski (Eds.), Logic, Methodology and the Philosophy of Science, pp. 252-261. Stanford: Stanford University Press.

Suppes, P. (2002). Representation and Invariance of Scientific Structures. Stanford: CSLI Publications.

van Benthem, J. (1989). "What is dialectical logic?" Erkenntnis 14, 333-347.

van Benthem, J. (2012a). Foreword. Argument \& Computation, A Special Issue on an Equational Approach to Argumentation.

(C) John Woods. Informal Logic, Vol. 33, No. 2 (2013), pp. 292-331. 


\section{John Woods}

van Benthem, J. (2012b). "The nets of reason." Argument \& Computation, A Special Issue on an Equational Approach to Argumentation, 83-86.

van Fraassen, B.C. (1984). "Belief and the will." Journal of Philosophy 81, 235-256

van Fraassen, B.C. (1990). "Figures in a probability landscape.” In J.M. Dunn and A. Gupta (Eds.), Truth or Consequences, pp. 345-356. Dordrecht: Kluwer.

van Fraassen, B.C. (1999). "Conditionalization, a new argument for." Topoi 18, 93-96.

von Plato, J. (1994). Creating Modern Probability Theory. Cambridge: Cambridge University press.

Walton, D. (1998). The New Dialectic: Conversational Contexts of Argument. Toronto: University of Toronto Press.

Walton, D. and Krabbe, E.C.W. (1995). Commitment in Dialogue. Albany: State University of New York Press.

Weinstein, M. (2013). Logic, Truth and Enquiry. London: College Publications.

Woods, J. (2001). "Pluralism about logical consequence: Conflict resolution in logic." In J. Woods and B. Brown (Eds.), Logical Consequence: Rival Approaches, pp. 39-54. Oxford: Hermes Science Publications.

Woods, J. (2003). Paradox and Paraconsistency: Conflict Resolution in the Abstract Sciences. Cambridge: Cambridge University Press.

Woods, J. (2011). "MacColl's elusive pluralism." In A. Moktefi and S. Read (Eds.), Hugh MacColl After One Hundred Years. A special number of Philosophia Scientiae 15, 163-189.

Woods, J. (2012). “Semantic penumbra.” Topoi 31, 121-134.

Woods, J. (2013a). Errors of Reasoning: Naturalizing the Logic of Inference. London: College Publications.

Woods, J. (2013b). "Against fictionalism." To appear in ModelBased Reasoning in Science and Technology, Theoretical and Cognitive Issues. Berlin: Springer.

Woods, J., Irvine, A. and Walton, D. (2004). Argument. Toronto: Prentice-Hall.

(C) John Woods. Informal Logic, Vol. 33, No. 2 (2013), pp. 292-331. 
Epistemology Mathematicized 331

Woods, J. and Rosales, A. (2010). "Virtuous distortion in modelbased science." In Lorenzo Magnani, Walter Carnielli, and Claudio Pizzi (Eds.), Model-Based Reasoning in Science and Technology: Abduction, Logic and Computational Discovery, pp. 3-30. Berlin: Springer.

(C) John Woods. Informal Logic, Vol. 33, No. 2 (2013), pp. 292-331. 